\title{
METAFORIZANDO AS NARRATIVAS DE SI: UMA ARTE EM PROSA
}

\section{NORINÊS PANICACCI BAHIA}

Universidade Metodista de São Paulo

RESUMO Considerando os avanços dos estudos e pesquisas relacionados às abordagens (auto)biográficas, bem como a sua consolidação nos processos de formação de professores, apresentamos, neste artigo, uma revisão bibliográfica em torno das discussões e proposições de autores da área. Pela sua reconhecida colaboração para a compreensão de sua gênese e das atuais reflexões e investigações que apontam para as possibilidades de desvelamento da identidade docente, enquanto importante recurso reflexivo, formativo e de pesquisa, destacamos os estudos de Nóvoa (1992b), Nóvoa e Finger (1988), Josso (1988; 2004), Cunha (1997); Bueno (2002), Bolivar (2012), Souza e Bragança (2012), Passeggi e Abrahão (2012) e Catani (2014), apenas para citar alguns exemplos. Ampliamos as discussões, apresentando uma possibilidade de trabalho com as narrativas de si que recorre a uma metáfora, em interface com o processo de confeção de uma colcha de retalhos - uma abordagem que une teoria e prática, pelo viés da expressividade das representações de momentos-charneira "em retalhos", a partir das muitas e variadas trajetórias formativas e profissionais dos sujeitos envolvidos nesse processo. As análises realizadas indicam a riqueza das reflexões e das práticas de processos formativos que não só desvelam elementos constitutivos da profissionalidade docente, como também do seu fortalecimento - uma identidade que se consolida, também, pelas reflexões dos saberes e fazeres de um sujeito em suas experiências, certezas e incertezas, e na interação com outros sujeitos e contextos.

Palavras-chave: (Auto)biografia. Narrativas de si. Momentos-charneira. Formação docente.

\section{ABSTRACT METAPHORIZING SELF-NARRATIVES: ART IN PROSE}

Considering the advances in studies and research concerning (auto) biographical approaches as well as their consolidation in teacher's training processes, we present a bibliographical review of studies by authors who have greatly contributed to the appearance and development of reflections and investigations leading to the possibilities 
of revealing the teacher's identity as an important, reflexive, formative resource. Among those authors are Nóvoa (1992b); Nóvoa and Finger (1988); Josso (1988, 2004); Cunha (1997); Bueno (2002); Bolivar (2012); Souza and Bragança (2012); Passeggi and Abrahão (2012); Catani (2014), just to mention a few. From previous considerations, we expand discussions to include the possibility of dealing with self-narratives, seen as a metaphor of making a patchwork quilt - an approach that combines theory and practice by means of expressive representations of "patchworking" hinge moments that participants have gone through during their formative and professional life. Our analyses show the richness contained in such reflections and formative processes, revealing developmental elements related to teacher's professionality, and to its strengthening - an identity that is consolidated by reflections involving participant's experiences, certainties and uncertainties in interaction with other participants and contexts.

Keywords: (Auto)biography. Self-narratives. Hinge-moments. Teacher's training.

\section{RESUMEN METAFORIZANDO LAS NARRATIVAS DE SI: UN ARTE EN}

\section{PROSA}

Considerando los avances de los estudios y de las investigaciones relacionados a los abordajes (auto)biográficos, tanto como su consolidación para los procesos de formación de profesores, presentamos en este artículo una revisión bibliográfica en torno de las discusiones y proposiciones de autores del área por la reconocida colaboración para la comprensión de la génesis de su surgimiento y de las actuales reflexiones e investigaciones que apuntan para las posibilidades del desvelamiento de la identidad docente como importante recurso reflexivo, formativo y de investigación - como en Nóvoa (1992b); Nóvoa y Finger (1988); Josso (1988, 2004); Cunha (1997); Bueno (2002); Bolívar (2012); Souza y Bragança (2012); Passeggi y Abrahão (2012); Catani (2014), solo para citar algunos ejemplos. A partir de eso, ampliamos las discusiones presentando una posibilidad de trabajo con las narrativas de sí, que recurre a una metáfora en interfaz con el proceso de confección de una colcha de retazos - un abordaje que une teoría y práctica por el bies de la expresividad de las representaciones de momentos bisagra "en retazos", a partir de las muchas y variadas trayectorias formativa y profesional de sujetos envueltos en ese proceso. Los análisis realizados indican la riqueza de las reflexiones y de prácticas de procesos formativos que no 
solamente desvelan elementos constitutivos de la profesionalidad docente, como también de su fortalecimiento - una identidad que se consolida, también, por las reflexiones de los saberes y haceres de un sujeto en sus experiencias, certezas e incertezas, y en la interacción con otros sujetos y contextos.

Palabras clave: (Auto)biografia. Narrativas de sí. Momentos-bisagra. Formación docente.

\section{Introdução}

A memória como presença viva do passado pessoal-coletivo, em suas lembranças e esquecimentos, manifesta-se nos sujeitos da pesquisa-formação pela narrativa que recria o passado, encaminhando novos projetos de futuro. Um movimento de memória-narração prenhe de dimensões sócio-históricas, de espaçostempos que se entrecruzam em trajetórias de vida pessoais-coletivas. (SOUZA; BRAGANÇA, 2012, p. 22-23)

A citação acima, como uma inspiração, nos remete à consideração de que os estudos e pesquisas sobre as narrativas (auto)biográficas acenam para a possibilidade do resgate da identidade docente e, também, como um processo necessário não só para o fortalecimento do eu individual-profissional-coletivo, mas, especialmente, para a compreensão e o enfrentamento do cotidiano profissional que, por vezes, faz parte de um contexto conturbado, complexo e contraditório, que muitos profissionais da área da educação vivenciam.

Não há dúvida de que as nossas experiências formativas e/ou profissionais são marcadas por nossas decisões/indecisões, acertos/ erros e também por conflitos, e esses elementos, quando refletidos, revelam momentos marcantes, de rupturas, de transformações, de posicionamentos, de escolhas - denominados "momentos-charneira":

[ ] a narrativa articula períodos da existência que reúnem vários 'factos' considerados formadores. A articulação entre estes períodos efectua-se em torno de 'momentos-charneira', designados como tal porque o sujeito escolheu - sentiu-se obrigado a - uma reorientação na sua maneira de se comportar e/ou na sua maneira de pensar o seu meio ambiente e/ou de pensar em si através de novas actividades. Estes momentos de reorientação articulam-se com situações de conflito e/ou com mudanças de estatuto social, e/ou com relações humanas particularmente intensas, e/ou com acontecimentos sócio-culturais (familiares, profissionais, políticos e económicos). (JOSSO, 1988, p. 43-44)

O desvelamento desses períodos, por rememoração das diferentes fases pelas quais passamos, são fundamentais para a compreensão/consciência do nosso lugar, nossas decisões, nossas marcas. Trata-se de um "caminhar para si" (JOSSO, 2004), para se conhecer por meio dos tantos caminhos percorridos, por diferentes lugares e tempos, e na relação com tantas outras pessoas.

Isso significa que os sujeitos possuem uma história muito própria - com várias memórias do passado e do presente - e a recuperação dessas, com a ressignificação dos fragmentos do passado, em interface com a reflexão no presente, promove projeções para o futuro:

[ ] as histórias de vida constroem-se numa perspectiva retroactiva (do presente para o passado) e procuram projectar-se no futuro; a formação deve ser entendida como uma tomada de consciência reflexiva (presente) de toda uma trajectória de vida percorrida no passado; é fundamental que a abordagem biográfica não deslize no sentido de favorecer uma atitude 'in- 
timista' (e não participada), na medida em que tal poderia dificultar a meta teórica a atingir, isto é, a compreensão a partir da história de vida de cada um do processo de formação dos adultos. (NÓVOA; FINGER, 1988, p. 15)

Cada sujeito é único e se diferencia pelas formas expressivas de suas representações sobre como vê e compreende o mundo, e as suas razões por determinadas escolhas. Em um sentido mais amplo, e inspirada em Josso (1988, p. 41), compreender por que sou do jeito que sou? e por que eu tenho as ideias que tenho?' são questões em evidência na utilização das narrativas de si como um processo que promove um encontro consigo mesmo, num movimento de análise e reflexão acerca de trajetórias formativas e profissionais de professores:

Em nossos dias, tornou-se um imperativo dizer quem somos, o que fazemos, explicar nosso percurso, falar de nossos projetos de vida. [...] A vida pessoal e a vida profisisonal se sobrepõem, tornam indissociáveis o público e o privado. [...] A disposição do humano a se tornar sujeito, mediante o ato de narrar a história de sua vida, constitui um postulado da pesquisa (auto)biográfica, fundamentado numa concepção filosófica do sujeito como ser capaz e pleno de potencialidades para se apropriar do seu poder e reflexão. Nesse sentido, é que as narrativas autorreferenciais são consideradas como objeto de estudo primordial para a pesquia (auto)biográfica, pois são suscetíveis de revelar os modos como os indivíduos de uma determinada época e cultura interpretam o mundo e como dão forma a suas experiências. (PASSEGGI; ABRAHÃO; DELORY-MOMBERGER, 2012, p. 3334 - grifos das autoras)

A partir dessas considerações iniciais, retomaremos brevemente o histórico do surgimento do método (auto)biográfico e o percurso da sua consolidação para a área da formação de professores, indo até as discussões e preocupações mais recentes acerca do mes-

1 Em Josso (1988, p. 41), as expressões utilizadas pela autora são: "como me tornei no que sou" e "como tenho eu as ideias que tenho". mo - e apresentaremos, também, uma prática possivel de utilização das narrativas de si, metaforizando-a pela tradição popular de confecção de colchas de retalhos - uma arte em prosa.

\section{O passado para a compreensão do presente}

Há aproximadamente 30 anos, os estudos sobre histórias de vida de professores ${ }^{2}$ foram sendo disseminados, especialmente pela via das discussões e das pesquisas (auto)biográficas, compondo um campo promissor para a construção de conhecimentos e saberes na área da formação de professores.

Não podemos deixar de mencionar a obra "O método (auto)biográfico e a formação", organizada em 1988 por Nóvoa e Finger que, sem dúvida, foi um marco em nosso contexto educacional sobre a importância de novos olhares e procedimentos para as discussões, ações e pesquisas, acerca da formação permanente de professores. Assim como as outras três obras organizadas por Nóvoa, em 1992 - "Os professores e a sua formação" (1992a), "Vidas de professores" (1992b) e "Profissão Professor" (1992c) -significaram um grande avanço para a apropriação das ideias e discussões pelos professores e pesquisadores brasileiros.

Essas obras mencionadas, e que apresentam as muitas reflexões e pesquisas de tantos outros autores - como Franco Ferrarotti, Christine Josso, Pierre Dominicé, Gaston Pineau, Adèle Chené, Donald A. Schön, Ken Zeichner, Michaël Huberman, Ivor F. Goodson, Thomas S. Popkewitz (apenas para citar alguns exemplos) - desvelam a ênfase que é dada, a partir da década de 1980, à pessoa do professor e que, segundo Bueno (2002, p. 11) “[...] veio favorecer o aparecimento de um grande número de

2 Neste artigo, no caso da revisão da literatura sobre "histórias de vida", faremos um recorte específico para a área da formação de professores. 
obras e estudos sobre a vida dos professores, as carreiras e os percursos profissionais, as autobiografias docentes ou o desenvolvimento pessoal dos professores".

É importante ressaltarmos que esse movimento evidenciou a subjetividade como um novo olhar não só para as discussões teóricas, mas, especialmente, para o desenvolvimento de pesquisas. Conforme Bueno:

Este é o aspecto que aos olhos dos pesquisadores se mostrou esquecido ou mesmo relegado nos tratamentos anteriores, e que por isso passou a se mostrar promissor para realimentar novos desenvolvimentos teóricos nessa área, que se encontrava paralisada diante do acúmulo de problemas e do desgaste causado pela indeficácia dos instrumentos de que dispunha até então. A subjetividade passa a se constituir, assim, na ideia nuclear, vale dizer, no próprio conceito articulador das novas formulações teóricas e das propostas que realimentam a área a partir dessa viragem. (2002, p. 13)

Essa questão da subjetividade pode ser considerada como a propulsora da aceitação para a utilização das abordagens investigativas do método (auto)biográfico e da recuperação das memórias, pela via das histórias de vida de professores, como uma ruptura necessária para os avanços da área da educação à época ${ }^{3}$ - porque inovadora e transcendente ao lugar comum. Souza amplia essa discussão ao afirmar que:

[ ] a abordagem biográfico-narrativa assume a complexidade e a dificuldade em atribuir primazia ao sujeito ou à cultura no processo de construção de sentido. Ao longo de seu percurso pessoal, consciente de suas idiossincrasias, o indivíduo constrói sua identidade pessoal mobilizando referentes que estão no coletivo. Mas, ao manipular esses referentes de forma pessoal e única, constrói subjetividades, tam-

3 Bueno (2002) evidencia que o método biográfico, apesar de recente na área da educação, era uma metodologia já empregada nas décadas de 1920 e 1930, pela área da sociologia (Escola de Chicago), como uma busca à superação da sociologia positivista. bém únicas. Nesse sentido, a abordagem biográfico-narrativa pode auxiliar na compreensão do singular/universal das histórias, memórias institucionais e formadoras dos sujeitos em seus contextos, pois revelam práticas individuais que estão inscritas na densidade da história. (2007, p. 65-66)

A década de 1990, no Brasil, mostra-se profícua no desenvolvimento de pesquisas e trabalhos sobre a profissão docente e, especialmente, sobre os processos de formação e profissionalização que evidenciam as discussões sobre as experiências dos professores:

Esses trabalhos, baseados nas histórias de vida como método de investigação qualitativa e como prática de formação, procuram identificar, nas trajetórias de professores, questões de interesse para a pesquisa educacional, entre as quais: as razões da escolha profissional, as especificidades das diferentes fases da carreira docente, as relações de gênero no exercício do magistério, a construção da identidade docente, as relações entre a ação educativa e as políticas educacionais. (PASSEGGI; SOUZA; VICENTINI, 2011, p. 370)

Os autores afirmam, ainda, que a partir dos anos de 2000 ocorre uma diversificação de abordagens que continuam nessa esteira de investigações, que se ancoram nas pesquisas (auto)biográficas como "um território comum e propício ao diálogo entre pesquisadores, em rede nacional e internacional." (PASSEGGI; SOUZA; VICENTINI, 2011, p. 370)

As investigações (auto)biográficas exigem um acompanhamento efetivo para se garantir a legitimidade do aproveitamento das discussões e análises realizadas e isso significa um olhar atento, sensivel e consciente, por parte do pesquisador e, também, o domínio das estratégias e conteúdos teórico-práticos sobre essa metodologia, para não se correr o risco das reflexões se perderem ou mesmo serem subutilizadas. Sobre isso, Catani apresenta considerações importantes: 
Talvez valesse a pena uma perspectiva de análise que permitisse apreender algo desses processos da vida educacional relatados, recuperados e estudados da vida dos indivíduos, pelo menos para que daí se pudesse constituir maneiras de tornar as classificações e sua produção algo do conhecimento de todos explicitando o seu poder de formação. Uma atenção dessa natureza tem tido seu desenvolvimento favorecido na formação de professores? Compreendem bem, eles, os seus próprios efeitos de formação sobre os alunos? E na educação dos próprios alunos, cuida-se para que possam compreender como a vida escolar vai constituindo seus modos de ser e viver? Há muito, no meu entender a esperar dos estudos educacionais e do que as próprias pessoas que experimentam a vida na escola possam relatar, testemunhar, escrever. (2014, p. 36, grifo da autora)

Podemos dizer que, hoje, os referenciais teóricos, epistemológicos e metodológicos, que abarcam a área da pesquisa (auto)biográfica já estão consolidados pelos inúmeros estudos e pesquisas amplamente discutidos, apresentados e publicados ${ }^{4}$ em nosso contexto educacional e que vêm representando significativos avanços para os modos de ser e de estar na profissão, traduzindo-se em várias perspectivas de análise e, também, pela recuperação das memórias das experiências e práticas pedagógicas, das descrições e das análises das trajetórias formativas e profissionais dos docentes e que permeiam, sobretudo, o cotidiano escolar e as práticas de ensino e de formação.

\section{A complexidade do cotidiano escolar e a coragem de narrar-se}

4 No Brasil, muitos estudos e pesquisas sobre o método (auto)biográfico são de autores de renome que, sem dúvida, vêm colaborando para a divulgação e a consolidação do mesmo - citando alguns exemplos: Elizeu Clementino de Souza, Maria da Conceição Passeggi, Filomena de Arruda Monteiro, Paula Perin Vicentini, Denice Barbara Catani, Maria Helena Menna Barreto Abrahão, Zeila de Brito Fabri Demartini, Belmira Oliveira Bueno, Maria Isabel da Cunha e Inês Ferreira de Souza Bragança.
Considerando a escola como um lócus legítimo e proficuo para a formação e a atuação profissional, não poderíamos deixar de mencionar a importância do cotidiano escolar que favorece a construção da profissionalidade docente, pela multiplicidade de saberes e fazeres do conjunto de professores que fazem parte dele e pela convivência e troca de experiências dos jeitos de ser professor.

Pesquisas nos/dos/com os cotidianos refletem os processos individuais e coletivos, as maneiras particulares como se criam conhecimentos nos cotidianos, buscando compreender as diferentes lógicas com que se articulam (ALVES, 2008). Isso significa que o cotidiano escolar é marcado por uma complexidade de relações, acontecimentos e vivências, em diferentes espaços e tempos, entre todos os que fazem parte de um contexto escolar, e os "olhares" sobre as práticas vividas e desenvolvidas comportam muitas possibilidades que vão muito além de revelar o que está por trás das rotinas, dos hábitos ou mesmo das repetições de um cotidiano.

Observamos um cenário de desgaste e de desvalorização da carreira docente que, infelizmente, acomete a categoria - e que gera sentimentos de desconforto e desânimo em muitos docentes. Em que pese a seriedade desse quadro e a urgente busca de estratégias para a sua superação, acreditamos que o desenvolvimento da metodologia (auto)biográfica - quer como pesquisa, quer como prática de ensino e de formação - poderia contribuir para o enfrentamento de sentimentos por vezes tão negativos manifestados por alguns professores, tendo em vista a possibilidade de darmos e/ou devolvermos a voz aos professores e aos seus pares, desvelando e valorizando os sentidos e significados sobre os seus saberes e fazeres docentes. Segundo Pérez:

A produção de narrativas autobiográficas como instrumento de formação e procedimento de 
investigação, nos permite encontrar nas singularidades, o excepcional-normal. Diferentes espaços-tempos, múltiplos percursos, experiências plurais, dobras e desdobras da memória e da palavra, fragmentos silenciosos/silenciados, escondidos/esquecidos de histórias que nos possibilitam descobrir/encontrar o estranho no banal. Narrativas singulares e plurais, fragmentos de memória que ao serem narrados (re) criam sentidos e produzem novos significados para a docência e para a vida. [...] A produção de narrativas autobiográficas possibilita às professoras a viverem o estado inédito de aprender/ praticar a assunção de si por si mesmas. [...] A escrita é a pauta a partir da qual as professoras vão percebendo/experimentando situações limites, ampliando suas fronteiras e desatando os nós do medo e da estagnação para produzir/ fabricar novos significados para a experiência e o conhecimento. $(2006$, p. 187)

É preciso considerarmos também que a proposição de investigações a partir das narrativas (auto)biográficas, que recuperam as trajetórias formativas e profissionais, pode não ser uma atividade tranquila, por ser um processo muito particular que envolve um encontro consigo mesmo sobre experiências e relações que se estabeleceram e/ou são estabelecidas em uma determinada época, tempo e lugar:

[...] demanda entrar em contato com diferentes memórias, representações, subjetividades e narrativas que o processo identitário comporta. [...] 0 resgate da história de vida e a própria narração da história permitem compreender o modo como cada sujeito, permanecendo ele próprio, se transforma. Também evidencia o processo e movimento que cada pessoa empreende para externalizar seus conhecimentos, valores, máscaras, as suas energias, para ir construindo a sua identidade, num diálogo contínuo com os seus contextos. (SOUZA, 2004, p. 152-153)

Assim, podemos afirmar que "narrar-se" envolve um processo autoformativo, a partir da análise do passado, refletido no presente e com projeções para o futuro, e trabalharmos com narrativas de diferentes sujeitos significa a participação e o envolvimento nos relatos destes, na reconstrução de significados e na compreensão dos sentidos dos que "se narram" - o que envolve a construção de vínculos e de confiança:

Falar de recordações-referências é dizer, de imediato, que elas são simbólicas do que o autor compreende como elementos constitutivos da sua formação. A recordação-referência significa, ao mesmo tempo, uma dimensão concreta ou visivel, que apela para as nossas percepções ou para as imagens sociais, e uma dimensão invisivel, que apela para emoções, sentimentos, sentido ou valores. A recordação-referência pode ser qualificada de experiência formadora, porque o que foi aprendido (saber-fazer e conhecimentos) serve, daí para a frente, quer de referência a numerosíssimas situações do gênero, que de acontecimento existencial único e decisivo na simbólica orientadora de uma vida. São as experiências que podemos utilizar como ilustração numa história para descrever uma transformação, um estado de coisas, um complexo afetivo, uma idéia, como também uma situação, um acontecimento, uma atividade ou um encontro. E essa história me apresenta ao outro em formas sócio-culturais, e representações, conhecimentos e valorizações, que são diferentes formas de falar de mim, das minhas identidades e da minha subjetividade. (JOSSO, 2004, p. 40-41)

As análises dos conteúdos das narrativas geralmente são muito ricas. porque delas emergem e são valorizadas as vozes dos professores, com o desvelamento de suas alegrias e tristezas, suas seguranças e inseguranças, suas representações, seus sentimentos, suas escolhas - marcas da trajetória formativa e profissional resgatadas pelas memórias de experiências passadas e presentes:

Trabalhar com a memória, seja a memória institucional ou a do sujeito, faz emergir a necessidade de se construir um olhar retrospectivo e prospectivo no tempo e sobre o tempo recons- 
tituído como possibilidade de investigação e de formação de professores. A memória é escrita num tempo, um tempo que permite deslocamento sobre as experiências. Tempo e memória que possibilitam conexões com as lembranças e os esquecimentos de si, dos lugares, das pessoas, da família, da escola e das dimensões existenciais do sujeito narrador. (SOUZA, 2007, p. 63-64)

A recuperação da identidade docente, pela via da pesquisa ou enquanto processo formativo, tem significativa importância não só pela valorização dos saberes e fazeres docentes, mas, sobretudo, pelo fortalecimento da profissionalização e da profissionalidade - um fortalecimento que pode auxiliar no enfrentamento das dificuldades e da desvalorização da carreira, que se apresentam em nosso contexto educacional.

\section{Uma arte em prosa entre as} narrativas de si e a tradição popular de confecção de colchas de retalhos - uma prática possivel

Como já discutido, a proposição da elaboração de narrativas de si comporta uma ação de conhecer a si mesmo, que revela não só os aspectos formativos, mas também os jeitos de ser e de estar na docência - um exercício que faz o sujeito analisar as suas tantas e diferentes experiências, a partir de diferentes lugares, tempos, contextos e suas relações com outros sujeitos - e que geralmente faz emergir descobertas, emoções, conflitos, coerências e incoerências, opções, imposições, idas-e-vindas:

Vida, profissão e narrativa estão entrecruzadas com relações territoriais e de poder, na medida em que remetem o sujeito a viver sua singularidade, enquanto ator e autor, investindo em sua interioridade e conhecimento de si e estimulando questionamentos sobre suas identidades, reveladas nas escritas do eu. Nesse ce- nário, trajetórias de vida e fragamentos biográficos articulam-se através de ações coletivas, aprendizagem informal e experiências sociais como constitutivas das culturas, identidades, subjetividades e diversidades dos sujeitos em seus territórios de vida-formação. (SOUZA, 2011, p. 213)

A descrição dessa prática e as reflexões que proponho nesse item possuem, na sua essência, uma metáfora que vem fazendo parte das minhas reflexões e pesquisas - sobre trajetórias formativas e profissionais de professores em interface com a tradição popular do processo de confecção de colchas de retalhos - uma ideia que me surgiu há muito tempo e que a tenho utilizado em algumas atividades e, mais recentemente, na proposição de uma disciplina que ministro no contexto de um programa de pós-gradução em educação.

Inicialmente, para situar os leitores sobre como me apropriei dessa ideia, a mesma surgiu a partir de uma experiência que tive, no ano de 2004, como colaboradora de um grupo de pesquisa na universidade na qual atuo desde 1999, quando realizávamos uma investigação sobre as trajetórias formativas e profissionais de alunas de um curso de pedagogia (grupo em que participei de 2000 a 2010).

Nas discussões desse grupo, estávamos pensando em formas possiveis de expressarmos as nossas análises dos dados coletados junto às alunas do curso, e propus a utilização de uma forma metaforizada pelo processo de confecção de uma colcha de retalhos - uma ideia inspirada pelo filme "Colcha de Retalhos" ("How to make an american quilt", USA, 1995), ${ }^{5}$ que apresenta a tradição popular da prática de confecção de colchas que são ligadas às trajetórias familiares em que a organização de partes (os retalhos), num todo articulado e harmonioso (a confecção da colcha), conta a história de uma família.

5 No anexo, apresento uma sinopse desse filme, bem como uma breve história sobre patchwork e quilt. 
Por considerar muito interessante essa tradição, fui me apropriando da mesma como uma metáfora possivel para a descrição, representação e análise de trajetórias formativas e profissionais em que, cada retalho, pode ser representado pelos períodos, processos vividos ou momentos-charneira, que se traduzem pelas experiências significativas - retalhos que vão compondo e construindo uma história de vida.

Mas essa sugestão que dei nesse grupo de pesquisa em 2004, não foi aceita, ficando a mesma somente no plano das minhas ideias até o ano de 2007, quando a mesma foi utilizada, de forma adaptada, para a organização de uma atividade avaliativa em um módulo de um curso de pedagogia a distância (que coordenei de 2006 a 2010), em que os alunos, em grupos, dos diferentes polos de apoio presencial, confeccionaram "colchas de retalhos", representando uma sintese sobre os temas e conteúdos trabalhados no 1 으 semestre de 2007 desse curso.

Foi somente em 2009 que concretizei, efetivamente, a ideia de escrever sobre a minha trajetória formativa e profissional, metaforizando-a pelo processo de confecção de uma "colcha de retalhos", por meio de um artigo publicado em que expressei os diferentes períodos da minha vida - desde a opção por ser professora até a inserção num programa de pós-graduação em educação - com a recuperação de memórias de mais de 30 anos do meu percurso formativo e profissional, em que cada período foi representado por um "retalho". E, em 2013, por ocasião da apresentação do meu memorial, como parte da proposta de projeto de pesquisa para a realização do estágio pósdoutoral (finalizado em 2014), retomei esse artigo, escrito em 2009, ampliando-o e complementando-o com outras experiências vivenciadas - outros "retalhos" - que fazem parte da minha trajetória, como num "continuum" e em permanente construção.
Diante dessas experiências, pelo amadurecimento das minhas leituras e reflexões sobre (auto)biografias e, especialmente, pela positividade percebida nos discursos e/ou depoimentos dos que vem, comigo, compartilhando e vivenciando o desenvolvimento de algumas atividades, considerei que poderia ampliar mais as possibilidades de práticas formativas com a utilização da metáfora já mencionada que analisa trajetórias formativas e profissionais em interface com a tradição popular de confecção de colchas de retalhos - que estou denominando como a "arte em prosa".

Considerando a tradição de confecção de colchas de retalhos, como uma "arte popular" - como aquela ligada à intuição, à expressividade de crenças, histórias, costumes de uma determinada cultura, família ou cotidiano e que possui, geralmente, um significado muito particular - atrelamos a ideia de "prosa", compreendida como um discurso direto, livre, como a expressão natural de uma linguagem e que pode recorrer a metáforas.

Assim, recentemente (no primeiro semestre de 2016), propus e desenvolvi uma disciplina eletiva no programa de pós-graduação em que atuo, e que tem como um dos objetivos discutir a importância do resgate da memória educativa, através das trajetórias formativas e profissionais (as narrativas de si), para a compreensão da constituição da identidade profissional. Foram propostas leituras e discussões de autores de renome que colaboram com as discussões em torno de temas como experiências de vida e formação de professores; pesquisa (auto)biográfica; histórias de vida; profissão e profissionalidade docente; identidade docente; narrativas de si; memórias das trajetórias formativas e profissionais.

6 Apenas para esclarecer, o significado dessa ideia sobre "prosa" é de livre compreensão, simplificadamente. Consideramos não haver necessidade da utilização do conceito literário e aprofundado de "prosa", para o sentido que queremos apresentar. 
[...] uma abordagem biográfica específica nos campos dos conhecimentos ensinados é perfeitamente possivel como desencadeadora do processo de conhecimento e de aprendizagem. Trata-se, então, de trabalhar como nossos aprendizes sobre as mais diversas experiências com as quais se possa colocá-los em contato com nossos temas de trabalho e sobre o interesse de conhecimento que está em jogo para eles em nosso ensino. (JOSSO, 2006, p. 24)

Além disso, durante o semestre, os alunos foram elaborando narrativas de si sobre as suas trajetórias formativas e profissionais orientação que receberam desde o primeiro dia de aula. Então, conforme iam se apropriando das leituras e reflexões acerca dos temas propostos, das discussões sobre o filme assistido ("Colcha de retalhos"), concomitantemente foram realizando esse exercício de escrita da sua própria história.

É importante destacarmos que esse processo nos remete à questão da "autoria" e recorremos a Passeggi e Cunha, quando explicitam que:

Como preconiza o movimento socioeducativo das histórias de vida em formação, desde os anos 1980, o ato de narrar sua própria vida ocasiona transformações de si quando a narrativa autobiográfica se realiza, notadamente, num processo de coinvestimento entre o formador e os formandos [...]. 0 autor será aqui compreendido como a pessoa que está no origem do ato de escrita e é por ele responsável. Nas narrativas autobiográficas, a pessoa que escreve é, ao mesmo tempo, o autor empírico do texto, o narrador e o protagonista do enredo da história. $(2013$, p. 45)

A proposição da escrita das narrativas teve um desdobramento, com a realização de um workshop intitulado "Colcha de Retalhos: nossas memórias, nossas histórias...", realizado ao final do semestre, como fechamento da disciplina. Nesse dia, além da entrega, por escrito, da narrativa de si, cada aluno apresentou também o "seu retalho" - um retalho que ex- pressou um momento marcante e significativo da sua narrativa/um "momento-charneira". A produção/representação de cada retalho foi a elaboração física do mesmo, em tecido, com pinturas, bordados, colagens - um retalho que também foi sendo confeccionado durante o semestre. Nesse workshop, todos apresentaram brevemente o significado dos seus retalhos e, após essa apresentação, o grupo se organizou para a composição/montagem da colcha de retalhos do grupo.

Essa experiência foi muito interessante, pois evidenciou o envolvimento de todos os alunos da disciplina (9 mulheres e 1 homem, dentre mestrandos e doutorandos), além do entusiasmo para a elaboração das narrativas de si, que deram origem aos retalhos e à colcha construída coletivamente. As histórias narradas, dos caminhos percorridos, revelaram a riqueza das experiências, dos conhecimentos e saberes desses alunos, além das emoções, das escolhas, dos acertos, dos erros, dos conflitos, das seguranças, das inseguranças, das alegrias e tristezas.

Josso apresenta reflexões importantes sobre o desenvolvimento de pesquisas com histórias de vida porque amplia a ideia, para além do objetivo meramente formativo e/ou profissional, considerando as questões existenciais dos sujeitos que estão ligadas ao mercado de trabalho, à satisfação profissional, às relações familiares, a aspectos psicológicos, ao contexto político, social e cultural:

Todos os relatos de histórias de vida, sem exceção, apresentam-se como uma sucessão ou uma co-habitação de buscas que valorizam aspectos particulares da existência: a felicidade, os conhecimentos sobre o mundo, o conhecimento de si e dos outros, a pesquisa de vínculos férteis, o sentido da vida, e, finalmente, o desenvolvimento de uma melhor acuidade de nossa capacidade de observação ou dito de outro modo de nosa atenção consciente. (JOSSO, 2006, p. 34-34) 
$\mathrm{Na}$ avaliação realizada dessa experiência, os depoimentos dos alunos foram fortes e emocionantes - ninguém havia realizado, ainda, esse exercício de recuperação das próprias memórias, e duas questões foram consideradas muito importantes: a primeira, que se referiu à estranheza sentida, inicialmente, na elaboração das narrativas por meio das memórias, e muitos se surpreenderam ao constatar as "muitas" memórias que possuíam de episódios ocorridos e que, com esse exercício, puderam compreendê-los melhor e também a si mesmos, num processo imbuído de muita emoção. A segunda questão, que se referiu à sensação de pertencimento e acolhimento do grupo, de cumplicidade, de solidariedade, de compartilhamento de situações por vezes comuns a alguns e, especialmente, por se sentirem ouvidos, respeitados e valorizados por suas histórias.

Sem dúvida, foi um trabalho prazeroso e envolvente - um movimento coletivo de descobertas, de emoções e de reflexões.

\section{Finalizando...}

Neste artigo, apresentamos uma breve recuperação do percurso e da consolidação, em nosso contexto, da metodologia das histórias de vida, com ênfase na pesquisa (auto)biográfica, que visa a recuperação das memórias sobre as trajetórias formativas e profissionais de professores - um processo que possibilita compreender os jeitos de ser e de estar na profissão, porque desvela a riqueza das experiências, das opções, dos saberes e fazeres construídos, das dúvidas e certezas, e tantas outras indicações que promovem uma reflexão centrada, do docente, colaborando para a percepção das suas formas de compreender melhor seu processo formativo e profissional, o seu cotidiano de atuação e, também, as relações com seus pares - do individual para o coletivo, na busca do equilíbrio das ações e relações.

Acreditamos que a utilização da investigação (auto)biográfica, enquanto processo de pesquisa, formação e ensino, se constitui um diferencial para a discussão dos conhecimentos, saberes e práticas, porque fundamental para a construção/constituição das identidades individuais e coletivas de professores.

O objetivo da experiência relatada com narrativas de si metaforizada pelo processo de confecção de uma colcha de retalhos, enquanto processo formativo, evidenciou a possibilidade de adentrarmos, a partir do particular, o mundo coletivo, para o desvelamento dos modos de ser de diferentes sujeitos e, como isso, agregou outros conhecimentos, outros saberes, outras descobertas sobre si mesmo:

A centração no indivíduo como agente e paciente, agindo e sofrendo no seio de grupos sociais, conduz cada vez mais a se investigar em Educação a estreita relação entre aprendizagem e reflexividade autobiográfica. Sendo essa última considerada enquanto a capacidade de criatividade humana para reconstruir a consciência histórica das aprendizagens realizadas ao longo da vida. (PASSEGGI; SOUZA; VICENTINI, 2011, p. 372)

Para finalizar, apresento a citação a seguir, por acreditar que ela expressa uma essência muito interessante sobre a profissão docente, nos inspirando e, também, nos dando um alento, especialmente pelo nosso cenário que, infelizmente, é permeado pela desvalorização dos docentes:

El maestro es um auténtico profesional de las relaciones humanas, un artesano en el proceso de construcción de las personalidades de sus estudiantes, además de ser una persona culta y sabia. De hecho, el maestro se vuelve un artesano que há decido poner sus manos a la obra, volcando sua creatividad, sus conocimientos, sus deseos en el acompañamiento de un nuevo sujeto. Entonces reflexionan en torno 
a sus prácticas docentes, crean nuevos conocimientos sobre la educación. Se hacen y rehacen a sí mismos al combinar y recombinar sus instrumentos de trabajo, al pensar y repensar sus formas de trabajo. Genera cambios al reflexionar y construir críticas y propuestas alterna- tivas em lo pedagógico, cuando sistematiza su experiencia, cuando escribe narraciones pedagógicas a partir de registros cotidianos, cuando piensa complejamente sobre los dilemas de la educación y no se deja abatir.? (PORTILLO, 2016, p. 39)

\section{Referências}

ALVES, Nilda. Sobre movimentos das pesquisas nos/ dos/com os cotidianos. In: OLIVEIRA, Inês Barbosa; ALVES, Nilda. (Orgs). Pesquisa nos/dos/com os cotidianos das escolas. 3. ed. Petrópolis, RJ: DP et Alii, 2008. p. 39-48.

BROUGÈRE, Gilles; ULMANN, Anne-Lise. (orgs). Aprender pela vida cotidiana. Tradução de Antonio de P. Danesi. Campinas, SP: Autores Associados, 2012. (Coleção Formação de Professores).

BUENO, Belmira O. O método autobiográfico e os estudos com histórias de vida de professores: a questão da subjetividade. Educação e Pesquisa, São Paulo, v. 28, n. 1, p. 11-30, jan./jun. 2002.

BOLÍVAR, Antonio. Metodología de la investigación biográfico-narrativa: recogida y análisis de datos. In: PASSEGGI, Maria da Conceição; ABRAHÃO, Maria Helena M. B. (Orgs.). Dimensões epistemológicas e metodológicas da pesquisa (auto)biográfica. Porto Alegre: EDIPUCRS; Natal: EDUFRN; Salvador: EDUNEB, 2012. p. 79-109 (Coleção Pesquisa (Aauto)biográfica: temas transversais, II).

CAMARGO, Ana Maria F. de; MARIGUELA, Márcio. (Orgs). Cotidiano escolar - emergência e invenção. Piracicaba: Jacintha Editores, 2007.

CATANI, Denice B. Ficções teóricas e ficções (auto) biográficas: elementos para uma reflexão sobre ciência e formação no campo educacional. In: ABRAHÃO, Maria Helena M. B.; BRAGANÇA, Inês F. de S.; ARAÚJO, Mairce da S. (Orgs.). Pesquisa (auto)biográfica, fontes e questões. Curitiba, PR: CRV, 2014. p. 27-37.

CUNHA, Maria Isabel da. Conta-me agora! As narrativas como alternativas pedagógicas na pesquisa e no ensino. Rev. Fac. Educ., São Paulo, v. 23, n. 1-2, s./p., 1997. Disponível em: <http:// www.scielo.br/scielo.php?script=sci arttext\&pi$\mathrm{d}=$ S0102-25551997000100010 >. Acesso em: $05 \mathrm{dez}$. 2016.

JOSSO, Marie-Christine. Experiências de vida e formação. Tradução de José Claudino e Júlia Ferreira. São Paulo: Cortez, 2004.

JOSSO, Marie-Christine. Da formação do sujeito... ao sujeito da formação. In: NÓVOA, António; FINGER, Matthias. (Orgs.). 0 método (auto)biográfico e a formação. Tradução de Maria Nóvoa. Lisboa: Pentaedro; Centro de Formação e Aperfeiçoamento Profissional, 1988. p. 35-50. (Cadernos de Formação, 1).

JOSSO, Marie-Christine. Os relatos de histórias de vida como desvelamento dos desafios existenciais da formação e do conhecimento: destinos sócioculturais e projetos de vida programados na invenção de si. In: SOUZA, Elizeu C.; ABRAHÃO, Maria Helena M. B. (Orgs.). Tempos, narrativas e ficções: a invenção de si. Porto Alegre: EDIPUCRS; Salvador: EDUNEB, 2006. p. 21-40.

NÓVOA, António. (Coord.). Os professores e a sua formação. Lisboa: Publicações Dom Quixote, 1992a.

7 Tradução livre da autora deste artigo: “O professor é um autêntico profissional de relações humanas, um artesão no processo de construção das personalidades de seus alunos, além de ser uma pessoa culta e sábia. Na verdade, o professor torna-se um artesão que decidiu colocar suas mãos na obra, transformando sua criatividade, seus conhecimentos, seus desejos no acompanhamento de um novo sujeito. Em seguida, pondera sobre suas práticas docentes, criando novos conhecimentos sobre educação. O professor faz-se e se refaz a si mesmo, ao combinar e recombinar seus instrumentos de trabalho, ao pensar e repensar suas formas de trabalho. Gera mudanças ao refletir e construir críticas e propostas pedagógicas alternativas, quando sistematiza sua experiência, quando escreve narrativas pedagógicas a partir de registros cotidianos, quando pensa complexamente sobre os dilemas da educação e não se deixa abater". 
NÓVOA, António. (Org.). Vidas de professores. Porto: Porto Editora, 1992b.

NÓVOA, António. (Org.). Profissão professor. Porto: Porto Editora, 1992c.

NÓVOA, António; FINGER, Mathias. (Orgs.). 0 método (auto)biográfico e a formação. Tradução de Maria Nóvoa. Lisboa: Pentaedro; Centro de Formação e Aperfeiçoamento Profissional, 1988. (Cadernos de Formação, 1).

PASSEGGI, Maria da Conceição; SOUZA, Elizeu C.; VICENTINI, Paula P. Entre a vida e a formação: pesquisa (auto)biográfica, docência e profissionalização. Educação em Revista, Belo Horizonte, v. 27, n.1, p. 369-386, abr. 2011.

PASSEGGI, Maria da Conceição; ABRAHÃO, Maria Helena M. B. (Orgs.). Dimensões epistemológicas e metodológicas da pesquisa (auto)biográfica. Porto Alegre: EDIPUCRS; Natal: EDUFRN; Salvador: EDUNEB, 2012. (Coleção Pesquisa (Auto)biográfica: temas transversais, II).

PASSEGGI, Maria da Conceição; ABRAHÃO, Maria Helena M. B.; DELORY-MOMBERGER, Christine. Reabrir o passado, inventar o devir: a inenarrável condição biográfica do ser. In: PASSEGGI, Maria da Conceição; ABRAHÃO, Maria Helena M. B. (Orgs.). Dimensões epistemológicas e metodológicas da pesquisa (auto)biográfica. Porto Alegre: EDIPUCRS; Natal: EDUFRN; Salvador: EDUNEB, 2012. p. 29-57. (Coleção Pesquisa (Auto)biográfica: temas transversais, II).

PASSEGGI, Maria da Conceição; CUNHA, Luciana Medeiros. Narrativas autobiográficas: a imersão no processo de autoria. In: VICENTINI et al. (Orgs.). Pesquisa (auto)biográfica - questões de ensino e formação. Curitiba: CRV, 2013. p. 43-57.

PÉREZ, Carmem L. V. Histórias de escola e narrativas de professores: a experiência do GEPEMC. Memória e Cotidiano. In: SOUZA, Elizeu C. (Org.). Autobiografias, histórias de vida e formação: pesquisa e ensino. Porto Alegre: EDIPUCRS; Salvador: EDUNEB, 2006. p. 177-188.

PORTILLO, Jorge Alberto C. Hablar, leer, escribir, sentir, imaginar. La necesidad de crear uma narrativa desde la cultura escrita y el ser maestra/o em procesos de formación docente. In: MONTEIRO, Filomena de A. et al. (Orgs). Narrativas docentes, memórias e formação. Curitiba: CRV, 2016. p. 29-41. (Pesquisa (Auto)biográfica: conhecimentos, experiências e sentidos, 3).

SOUZA, Elizeu C. de. 0 conhecimento de si: narrativas do itinerário escolar e formação de professores. 2004. 344 f. Tese (Doutorado em Educação) - Faculdade de Educação, Universidade Federal da Bahia, Salvador, 2004. Disponivel em: <https://repositorio. ufba.br/ri/bitstream/ri/10267/1/Tese Elizeu\%20 Souza.pdf>. Acesso em: 04 dez. 2016.

SOUZA, Elizeu C. de. (Auto)biografia, histórias de vida e práticas de formação. In: NASCIMENTO, A. D.; HETKOWSKI, T. M. (Orgs.). Memória e formação de professores. [on-line]. Salvador: EDUFBA, 2007. p. 59-74. Disponivel em: <http://books.scielo.org>. Acesso em: 04 dez. 2016.

SOUZA, Elizeu C. de. Territórios das escritas do eu: pensar a profissão - narrar a vida. Educação, Porto Alegre: PUCRS, v. 34, n. 2, p. 213-220, mai./ago. /2011.

SOUZA, Elizeu C. de.; BRAGANÇA, Inês Ferreira de S. (Orgs.). Memória, dimensões sócio-históricas e trajetórias de vida. Porto Alegre: EDIPUCRS; Natal: EDUfRN; Salvador: EDUNEB, 2012. (Coleção Pesquisa (Auto)biográfica: temas transversais, 5).

\section{Anexo}

\section{Sinopse do filme "Colcha de retalhos"}

O filme "Colcha de Retalhos" ("How to Make an American Quilt", EUA, 1995) é narrado pela protagonista (interpretada por Winona Rider), que está noiva, fazendo mestrado e que vai passar um tempo na casa de uma tia-avó para concluir a sua dissertação. A trama desenrola-se a partir da relação dela com um grupo de sete mulheres (sua avó, sua tia-avó e mais 5 amigas), que formam um "clube da costura" e que realizam reuniões diárias para a confecção de colchas. Este grupo define um tema para a criação de uma colcha que será dada como presente de casamento para a protagonista - 
o tema é: "onde vive o amor". As bordadeiras têm como missão desenvolver, cada uma, um retalho, que represente a sua compreensão sobre o tema. A partir da confecção de cada retalho, o filme apresenta o passado das vidas destas bordadeiras - o que significa que, cada retalho, estampa este passado - as alegrias e decepções, os desejos e frustrações, as escolhas de cada uma em suas vidas. 0 grande desafio, para a confecção da colcha, está nas mãos de uma bordadeira mestra - uma negra idosa, empregada da tia-avó da protagonista que tem como missão juntar as peças/retalhos diferentes numa composição harmoniosa, com equilíbrio, para representar o tema definido. Segundo esta bordadeira mestra, estas colchas (na tradição de algumas famílias negras) possuem sempre um tema ligado ao passado das famílias. As colchas, então, passadas de geração em geração, contam uma história que precisa ser lida por meio de seus desenhos e composição - numa espécie de tradição oral, a história das famílias, bem como a arte da confecção das colchas, é transmitida assim.

\section{Breve história sobre patchwork e quilt ${ }^{8}$}

O trabalho manual sempre esteve presente no dia a dia dos povos desde seus primórdios. Por meio do artesanato, verificamos as tradições e os costumes regionais de uma época e localidade.

A origem do patchwork e do quilt é muito antiga. Existem registros desde 3400 a.C. Sua história nos mostra que a costura e os bordados já estavam presentes nas antigas civilizações do Egito, Pérsia, Índia e China, verificados, principalmente, nos acolchoados (quilts), encontrados nas tumbas de reis e rainhas dessa época, bem como nos desenhos registrados

8 Disponivel em: <http://www.ganhemaiscirculo.com. br/origens-do-patchwork-e-suas-principais-nomenclaturas/>. Acesso em: 04 dez. 2016. nas pirâmides com faraós usando uma vestimenta similar ao patchwork.

Mas foi na Europa Ocidental (Inglaterra, Alemanha, França e Itália), durante o século XVI (Cruzadas), que o trabalho do patchwork se desenvolveu mais fortemente. As roupas utilizadas por soldados embaixo das armaduras de ferro eram feitas com restos de tecidos. Nessa época, verifica-se que o patchwork tinha um caráter somente utilitário: ou para se usar como roupa ou para se proteger do frio intenso (colchas ou cobertores).

Fugindo das perseguições religiosas que sofriam na Europa, em meados do século XVII, os peregrinos e imigrantes ingleses colonizaram e desbravaram a América do Norte, levando, nas malas, para o Novo Mundo, suas colchas (seus quilts) e a tradição familiar do patchwork.

Estes colonizadores eram extremamente rígidos com suas esposas. Eles somente lhes permitiam sair de casa em duas situações: para irem à igreja ou para as reuniões de quilteiras, chamadas de quilting bees.

Os homens dessa época acreditavam que, se suas mulheres estivessem sempre com "as mãos ocupadas" fazendo colchas, não haveria espaço para maus pensamentos em suas cabeças.

Foi nesse momento da história que o patchwork foi difundido como uma técnica artesanal, eminentemente feminina e de tradição familiar, pois as quilting bees eram a única forma de socialização dessas mulheres. Elas passavam horas e horas juntas, conversando, debatendo e transformando os encontros em momentos longos e duradouros de liberdade de expressão, já que a figura masculina não estava presente.

Como as quilteiras permaneciam muitas horas em reunião, a técnica do patchwork começou a ganhar aperfeiçoamentos. Cada vez que se encontravam, essas mulheres não que- 
riam somente costurar uma simples colcha de retalhos, mas também começavam a estudar e a criar novas técnicas de desenhos e padronagens. Tudo isso para que os trabalhos demorassem mais tempo para finalizar, proporcionando mais horas de socialização das mulheres nas quilting bees.

Os quilts (as colchas) resultantes dessas reuniões expressavam todos os sentimentos mais íntimos, os desejos, as angústias e posições políticas dessas mulheres. Assim, aos poucos, o patchwork e o quilt passaram a ter, além do caráter utilitário que já possuíam, também um caráter decorativo e ornamental.

Aprovado em: 25/03/2017

Norinês Panicacci Bahia é Pós-Doutora em Educação, docente pesquisadora do PPGE da UMESP - Universidade Metodista de São Paulo. e-mail: noribahia@gmail.com

Rua do Sacramento, 230 - Rudge Ramos / São Bernardo do Campo

Tel: (11) 4366-5218 